\title{
Analisis Semiotika Tato Tradisional Suku Mentawai
}

\author{
Ian Handani, Suzy Azeharie \\ ianhandani@gmail.com,suzya@fikom.untar.ac,id \\ Fakultas Ilmu Komunikasi Universitas Tarumanagara
}

\begin{abstract}
This research is a qualitative research that discusses the traditional Mentawai Tribe tattoos. Tattoos are works of art that have the value and meaning of each image or motif. Research on the meaning of Mentawai tattoos is important to do because so far there is not much research on the meaning of the tattoo of the Mentawai community. The practice of the tattoo itself has been carried out from before Christ, precisely the first time in the Mentawai islands, West Sumatra. From year to year the specialization of traditional tattoos began to decline because they were considered ancient and outdated. Data from the research were taken from interviews with three speakers who had lived in Mentawai as well as documentation to obtain reliable data. The obtained data will be dissected with the semiotic theory of Charles Sanders Pierce's model that uses triangles meanings to analyze data and aims to determine the meaning and usefulness of the tattoos used by the Mentawai tribe. The conclusion of this study is that the Mentawai tribe considers tattoos to be a sacred thing because they relate to nature and spirits. From the results of the study there were two types of tattoos, including sarepak abak and sibalubalu. Each tattoo used by the Mentawai tribe also has a different meaning from each motif.
\end{abstract}

Keywords: Semiotics, Culture, Traditional Mentawai Tribe Tattoos

\begin{abstract}
Abstrak
Penelitian ini mengangkat tentang tato tradisional Suku Mentawai. Tato adalah sebuah karya seni yang memiliki nilai dan makna dari setiap gambar atau motifnya. Penelitian tentang makna tato Mentawai penting untuk dilakukan karena sejauh ini tidak banyak penelitian mengenai makna pada tato masyarakat Mentawai. Praktik tato sendiri sudah dijalankan mulai Sebelum Masehi tepatnya pertama kali di Kepulauan Mentawai, Sumatra Barat. Dari tahun ke tahun peminatan tato tradisional ini mulai menurun karena dianggap sudah kuno dan ketinggalan zaman. Data hasil penelitian diambil dari wawancara dengan tiga narasumber yang pernah tinggal di Mentawai serta dokumentasi, guna mendapatkan data yang bisa dipercaya. Data yang didapat akan dibedah dengan Teori Semiotika Model Charles Sanders Pierce yang memakai segitiga makna untuk menganalisa data dan bertujuan untuk mengetahui arti dan kegunaan dari tato yang dipakai oleh suku Mentawai. Kesimpulan dari penelitian ini adalah suku Mentawai mengganggap tato merupakan sebuah hal yang sakral karena berhubungan dengan alam dan arwah. Dari hasil penelitian ada delapan jenis tato antara lain sarepak abak dan sibalubalu. Setiap tato yang dipakai oleh suku Mentawai juga memiliki makna yang berbeda dari setiap motifnya.
\end{abstract}

Kata Kunci: Semiotika, Budaya, Tato Tradisional Suku Mentawai 


\section{Pendahuluan}

Kekayaan kebudayaan di Indonesia merupakan salah satu yang terbanyak dan terbesar di dunia. Menurut Badan Pusat Statistik pada tahun 2013 Indonesia memiliki lebih dari 633 suku yang menjadi salah satu kekayaan negeri ini. Salah satu dari suku tersebut adalah suku Mentawai yang merupakan salah satu suku tertua di Indonesia yang bermukim di bagian Barat pulau Sumatra. Menurut Krismato Kusbiantoro, pulau Mentawai terdiri dari pulau Siberut, pulau Sipora, pulau Pagai Utara dan pulau Pagai Selatan. Masyarakatnya masih memakai bahasa Melayu dan mereka lahir dengan kulit berwarna kuning-kecoklatan, rambut tipis dan mata sipit seperti masyarakat di Hawai atau suku Polynesian (Kusbiantoro, et al. 2016:187-188).

Seni menato tubuh merupakan tradisi yang ada di kepulauan Mentawai dan dikenal dengan sebutan titi. Alat yang digunakan oleh penato berbahan sangat sederhana yaitu dengan duri sebagai alat untuk memasukkan tinta ke dalam tubuh, arang batok kelapa sebagai zat pewarna hitam dan air tebu. Sebelum proses penatoan dimulai biasanya diselenggarakan sebuah pesta kecil yang disebut ulia sebagai bentuk penghormatan kepada roh leluhur agar diberikan kelancaran ketika sedang menjalani proses menato (Rumbiati \& Putra, 2015:117-118).

Penelitian Rosa berjudul Eksistensi Tato Sebagai Salah Satu Karya Seni Rupa Tradisional Masyarakat Mentawai menjelaskan bahwa tato pertama kali ditemukan di Indonesia pada tahun 1500 Sebelum Masehi yang memiliki makna dan kegunaan mendasar bagi penduduk kepulauan Mentawai. (Rosa, 1994:1). Seni tato menurut Hatib Abdul Kadir Olong dalam bukunya yang berjudul Tato, merupakan suatu kegiatan yang memiliki makna sakral. Secara historis, tato lahir dari budaya pedalaman tradisional bahkan dapat dikatakan kuno namun keberadaan menyebar luas hinga ke daerah perkotaan (Olong, 2006). Sementara menurut Dwi Marianto dan Syamsul Barry dalam buku yang berjudul Tato, kata tato dari kata tattoo, artinya adalah goresan, desain, gambar atau lambang yang dibuat pada kulit secara permanen (Marianto dan Barry 2002:2).

Menurut Dwi Marianto dan Syamsul Barry ada dua macam tato. Yang pertama tato permanen. Tato permanen adalah tetap dan tidak berubah-ubah. Artinya bahwa tato itu tidak bisa hilang kecuali dengan cara penyinaran dengan laser, pembedahan maupun pengamplasan. Teknik pembuatannya dengan memasukkan tinta atau perwarna ke dalam kulit dengan menusukkan jarum pada kulit. Lalu ada juga dengan membuat luka sayatan pada kulit yang kemudian diberi pewarna. Tato dengan teknik sayatan ini ditemukan pada suku di Papua, suku-suku di kawasan Pasifik dan sukusuku pedalaman Afrika. Awalnya terbentuk tato ini sangat sederhana, namun mempunyai makna khusus. Begitu juga alat yang digunakan tentunya masih sangat sederhana dan biasanya terbuat dari kayu atau bambu. Proses pembuatan tato mirip seperti orang yang memahat kayu.

Yang kedua tato temporer. Tato temporer adalah body art yang hasilnya tampak seperti tato, namun tidak menggunakan tusukan-tusukan jarum, dan tidak memasukkan tinta ke dalam kulit. Akan tetapi, tinta hanya ditempelkan di atas permukaan kulit saja dan tidak bisa tahan lama dalam arti bisa hilang dengan sendirinya. Jenis-jenis gambar tato ada dua macam yang pertama jenis flash yaitu tato yang banyak dipilih dan disukai, gambarnya sudah banyak dikenal seperti naga, hati dan jangkar. Jenis kedua adalah custom yaitu tato yang dibuat berdasarkan keinginan atau ide dari orang yang akan ditato. Custom ini dapat dibuat sendiri atau meminta bantuan dari tato artis (Marianto dan Barry, 2002:25). 
Charles Sanders Pierce dalam buku Rachmad Kriyantono yang berjudul Teknik Praktis Riset Komunikasi mengatakan bahwa penalaran manusia senantiasa dilakukan melalui tanda yang artinya manusia hanya dapat bernalar melalui tanda (sign), acuan tanda (object) dan penggunaan tanda (interpretant) atau disebut teori segitiga makna (Kriyantono, 2009:265).

Peneliti menggunakan teori semiotik Charles Sanders Pierce karena menganggap teori ini merupakan teori yang paling cocok untuk mengkaji makna tato tradisional suku Mentawai karena dari segitiga makna miliki Charles Sanders Pierce mengkaji tentang sign yang menjelaskan secara keseluruhan tentang bentuk, garis, titik dan lain lain. Sedangkan object yang menjelaskan tentang gabungan dari keseluruhan garis, bentuk, titik tato. Interpretant menjelaskan tentang kesimpulan dari arti tato tersebut.

\section{Metode Penelitian}

Pada penelitian ini penulis menggunakan metode penelitian kualitatif. Nana Syaodih Sukmadinata dalam buku yang berjudul Metode Penelitian Pendidikan penelitian kualitatif adalah penelitian yang digunakan untuk mendeskripsikan dan menganalisis fenomena, peristiwa, aktivitas sosial, sikap, kepercayaan, persepsi dan orang secara individual maupun kelompok (Sukmadinata, 2009:53). Menurut Lexy J. Moleong dalam buku yang berjudul Metodologi Penelitian Kualitatif merupakan penelitian yang bertujuan untuk memahami fenomena yang dialami oleh subjek penelitian misalnya perilaku, persepsi, motivasi dan tindakan secara holistik dengan cara deskripsi dalam bentuk kata-kata dan bahasa pada suatu konteks khusus yang alamiah dengan memanfaatkan berbagai metode alamiah (Moleong, 2009:6).

Berdasarkan penjelasan di atas penulis merangkum bahwa penelitian kualitatif merupakan penelitian melakukan pengamatan terhadap sekelompok manusia baik untuk memahami kejadian yang dialami seperti perilaku, persepsi atau tindakan sehingga menghasilkan data deskriptif berupa kata-kata tertulis dan menjadi alasan penulis untuk memilih pendekatan kualitatif deskriptif.

Penulis memakai metode penelitian semiotika untuk membedah hasil data yang didapat. Charles Sander Pierce dalam buku Benny H. Hoed dalam bukunya yang berjudul Semiotik \& Dinamika Sosial Budaya menjelaskan tanda tidak hanya mewakili sesuatu dan menerimanya. Jadi setiap tanda diberi makna oleh manusia dengan mengikuti proses yang disebutnya semiosis. Teori Pierce tentang tanda memerlihakan pemaknaan tanda menjadi suatu proses kognitif dan bukan sebuah setruktur. Proses seperti inilah yang disebut semiosis, yaitu suatu proses pemaknaan tanda yang bermula dari persepsi atas dasar, kemudian dasar merujuk pada objek dan akhirnya terjadi proses interpretant (Hoed, 2002:21).

Subjek penelitian yang digunakan dalam penelitian ini adalah suku Mentawai yang mengerti tentang praktik titi dan mengerti setiap makna yang terkandung dalam setiap tato yang diteliti oleh penulis.

Objek penelitian yang digunakan dalam penelitian ini merupakan tato tradisional suku Mentawai. Kemudian, objek penelitian tersebut dikuatkan dengan referensi dari studi pustaka, yaitu dengan memanfaatkan penelitian sebelumnya dan buku untuk semakin memperkuat data penelitian berhubung dengan penelitian yang sedang dikaji.

Data yang dihasilkan penulis didapat berdasarkan metode pengumpulan data observasi langsung ke Padang untuk melihat dan merasakan bagaimana proses penatoan, wawancara mendalam dengan beberapa narasumber (praktisi tato dan 
peneliti tato tradisional suku Mentawai), dokumentasi, studi pustaka dan data online. Menurut Lexy J. Moelong dalam bukunya yang berjudul Metode Penelitian Kualitatif triangulasi dengan sumber, berarti membandingkan dan melakukan pengecekan kembali derajat kepercayaan suatu informasi yang diperoleh melalui waktu dan alat yang berbeda. Dengan menggunakan teknik triangulasi peneliti dapat membandingkan data yaitu sebagai berikut:

1. Membandingkan data hasil pengamatan dengan data hasil wawancara.

2. Membandingkan data dengan narasumber ahli.

3. Membandingkan apa yang dikatakan orang di depan umum dengan apa yang dikatakan secara pribadi

4. Membandingkan apa yang dikatakan masyarakat tentang situasi penelitian dengan apa yang peneliti rasakan sepanjang waktu penelitian.

5. Membandingkan hasil wawancara dengan isi suatu dokumen yang berkaitan dalam pengujian keabsahan data (Moleong, 2010:330-331).

\section{Hasil Temuan dan Diskusi}

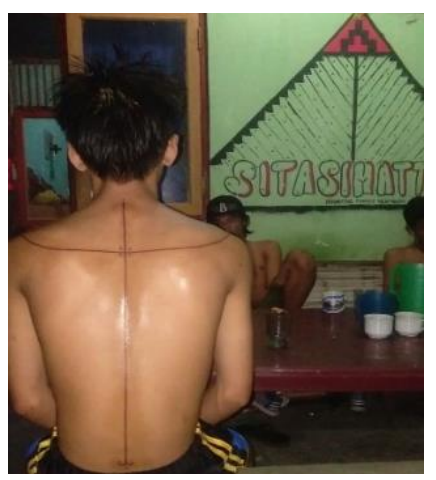

\section{Tanda}

Pada motif sarepak abak terdapat dua garis besar yang saling bersinggungan dengan empat titik pada titik temu antara kedua garis panjang serta satu titik di setiap ujung dari garis panjang.

ObjelĐari motif sarepak abak secara visual merupakan sebuah cadik sampan yang berguna sebagai penyeimbang kapal sampan dan beberapa dekorasi sebuah titik merupakan visualisasi bentuk nyamuk yang disebut dengan legew.

\section{Interpretasi}

Motif sarepak abak merupakan penegasan atas keseimbangan manusia, alam dan roh kepercayaan lokal Arat Sabulungan. Kepercayaan lokal penduduk tradisional Mentawai disebut Arat Sabulungan Kepercayaan ini memiliki tiga roh dewa pujaan yaitu roh laut (Tai Kabagat-Kaot), roh hutan dan pegunungan (Tai Ka-Leileu), dan roh awing-awang (Tai Ka-Manua). Kepercayaan ini menganggap bahwa setiap bendabenda memiliki arwah yang harus dirawat, jika tidak maka roh tersebut akan membawa nasib sial bahkan kematian.

Sarepak abak merupakan salah satu pilihan motif untuk membuat sebuah tato pertama kali karena bagi mereka keseimbangan dengan para roh dan alam salah satu hal penting untuk kelangsungan hidup. Motif sarepak abak biasanya dipakai oleh 
penduduk Mentawai yang hidup di pesisir pantai dan biasanya ditemukan di daerah Sagalube, Muara Simatalu, Muara Simalegi dan Pulikoman.

Cadik sampan difilosofikan sebagai sebuah keseimbangan yang menopang sampan ketika sedang berada di laut. Ombak laut yang tidak pasti bisa dengan mudah membuat sampan terbalik dan tenggelam. Sehingga ketika sampan dipasang sebuah cadik akan menghasilkan sebuah keseimbangan bagi sampan itu sendiri ketika ada ombak. Penduduk pesisir pantai tentu saja sangat bergantungan pada hasil laut yang di dapat. Bahkan dari pembuatan cadik sampan mereka juga memiliki sebuah acara adat atau ritual yang disebut punen abak rau lepa atau penyucian perahu dan enungna manek abak atau meramu persiapan pembuatan perahu. Ritual ini ditujukan kepada roh laut Tai Kabagat-Kaot agar pelaut diberikan kesehatan, keselamatan dan menolak bala ketika sedang mencari hasil laut.

Bentuk nyamuk yang disebut legew mengimpikasikan kondisi geografis sebuah wilayah yang mengindikasikan di sekitar tempat mereka tinggal banyak nyamuk sehingga dijadikan sebuah motif aksesoris.

Adapun pembagian tanda berupa index, symbol dan ikon pada bentuk tato sarepak abak. Ketiga unsur ini akan dipakai untuk dilakukan cross check dari data yang di dapat oleh penulis. Ikon yang menjadi sebuah relasi persamaan sebuah benda atau objek yang bisa dirasakan salah satu panca indra dan denotatumnya, sehingga dalam bentuk tato ini berupa bentuk cadik itu sendiri. Symbol yang merupakan ketergantungan atas adanya tanda itu sendiri. Jadi dalam motif tato ini merupakan garis-garis awal pembentuk sebuah motif tato suku Mentawai yaitu garis horizontal, garis vertikal dan bentuk spiral. Selain itu letak geografis seorang individu tinggal juga menjadi sebuah acuan tanda itu ada. Symbol adalah sebuah konvensi sehingga para penduduk memiliki tatanan yang disepakati oleh penduduk sekitar itu sendiri tanpa adanya sebuah kesepakatan maka sebuah symbol tidak akan bertahan.

Dengan demikian, ketika unsur tanda tersebut menjelaskan salah satu filosofi dari tato Mentawai yaitu Sarepak Abak yang berhubungan erat dengan roh kepercayaan lokal yang sampai sekarang masih dipegang oleh penduduk suku Mentawai. Tato juga dijadikan sebuah alat komunikasi antara sesama individu yang juga masih diakui hingga sekarang.

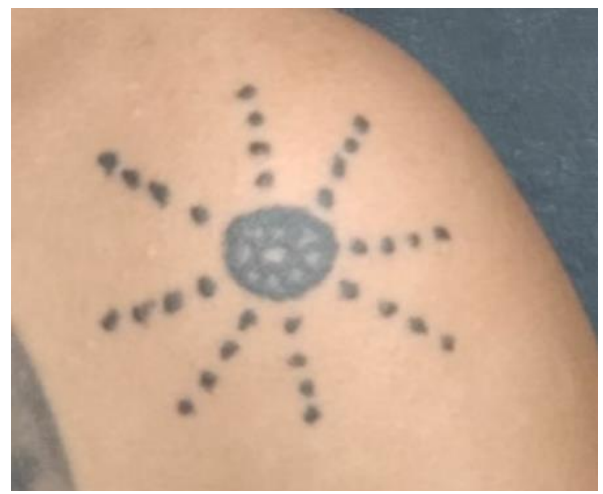

\section{Tanda}

Dari motif tato sibalubalu memiliki design yang cukup simpel yaitu lingkaran di tengah dan dikelilingi oleh garis lurus dalam bentuk titik sebanyak delapan sisi serta setiap sisinya terbentuk oleh empat titik. 


\section{Objek}

Secara visual sibalubalu merupakan gambaran sebuah bintang pleades atau matahari.

\section{Interpretasi}

Sibalubalu memiliki arti "delapan" yang artinya pemakaian motif ini harus diikut dengan delapan sisi dan sesuatu yang menjadi pusat dari delapan sisi tersebut. Motif ini juga melambangkan kesejahteraan. Secara mitologi awal dari terbentuknya motif sibalubalu berawal dari kepercayaan penghuni dunia atas atau dewa-dewa sebagai penguasa tertinggi di tatanan kehidupan. Tetapi dari faktanya bintang atau matahari merupakan sumber kehidupan, jika tidak ada matahari maka tidak ada kehidupan.

Motif tato sibalubalu seharusnya hanya boleh dipakai oleh sikerei yang merupakan seorang dukun yang merupakan penghubung komunikasi antara manusia dengan roh. Sebelum melakukan penatoan sikerei akan melaksanakan sebuah upacara sesajen berupa hasil buruan yang dipercaya penduduk lokal untuk melancarkan proses penatoan yang disebut sebagai punen patiti. Punen patiti merupakan upacara yang dijalankan sebelum penatoan guna melancarkan proses menato. Selain menjadi seorang dukun sikerei juga merupakan seorang tabib atau ahl obat-obatan. Penduduk sekitar juga percaya bahwa jika sikerei mengobati suatu penyakit maka yang melakukan penyembuhan adalah roh gaib yang diminta sikerei untuk mencarikan obat atau mengobati secara langsung.

Sebenarnya motif tato sibalubalu bisa dijadikan sebagai campuran dekorasi dari beberapa motif lainnya seperti misalnya motif sibalubalu jika diletakan di pusar perut wanita melambangkan kecantikan. Pemakaian motif tato sibalubalu diletakan di bagian pangkal bahu dan seandainya seorang individu telah memiliki motif ini, penduduk sekitar pasti sangat menghormati individu tersebut bahkan individu yang tidak memiliki tato motif sibalubalu tidak boleh berjalan di belakang individu yang memiliki motif ini. Motif ini juga tidak memiliki perbedaan yang signifikan antar tiap daerah, yang menjadi perbedaan hanya dekorasi yang menjadi pusat dari delapan garis tersebut. Tato ini juga dianggap salah satu tato yang dibuat pada pertama kali praktik tato di Mentawai karena dari bentuknya sangat simpel dan tidak ada modifikasi. Adapun pembagian tanda berupa index, symbol dan ikon pada bentuk tato sibalubalu. Ketiga unsur ini akan dipakai untuk dilakukan cross check dari data yang di dapat oleh penulis. Ikon yang menjadi sebuah relasi persamaan sebuah benda atau objek yang bisa dirasakan salah satu panca indra dan denotatumnya, sehingga dalam bentuk tato ini berupa bentuk bintang atau matahari itu sendiri. Symbol yang merupakan ketergantungan atas adanya tanda itu sendiri. Jadi dalam motif tato ini merupakan garis-garis awal pembentuk sebuah motif tato suku Mentawai yaitu garis horizontal, garis vertikal dan bentuk spiral. Selain itu letak geografis seorang individu tinggal juga menjadi sebuah acuan tanda itu ada. Symbol adalah sebuah konvensi sehingga para penduduk memiliki tatanan yang disepakati oleh penduduk sekitar itu sendiri. Tanpa adanya sebuah kesepakatan maka sebuah symbol tidak akan bertahan.

Motif tato ini juga bisa menggambarkan sebuah tatanan kehidupan yang menjadi instrument kepercayaan Arat Sabulungan. Karena dari penglihatan observasi walaupun mereka memiliki sebuah KTP yang memegang salah satu dari kelima agama yang diakui oleh pemerintah Indonesia penduduk Mentawai tetap memegang teguh kepercayaan yang dilandasi oleh Arat Sabulungan. Tidak hanya masyarakat pedalaman yang memegang kepercayaan ini, bahkan penduduk asli suku Mentawai 
yang sudah keluar dari pedalaman juga masih memegang kepercayaan Arat Sabulungan.

\section{Simpulan}

Pertama, tato Mentawai dijadikan simbol identitas diri masing-masing individu yang dianggap sebagai awal dan akhir kehidupan. Kedua, motif tato tradisional memiliki arti masing-masing. Ketiga, tato dijadikan sebagai instrument kepercayaan lokal. Keempat, tato tradisional diteruskan pada generasi selanjutnya dengan cara penghidupan kembali dan mengajarkan masyarakat penduduk Mentawai pengetahuan yang terkait dengan tato.

\section{Ucapan Terima Kasih}

Penulis mengucapkan rasa terima kasih yang sebesar-besarnya kepada seluruh pihak yang telah membantu dan mendukung penulis selama proses penelitian ini berlangsung sampai dengan terbitnya publikasi atas hasil penelitian ini.

\section{Daftar Pustaka}

Barry, Syamsul. \& Marianto, M. Dwi. (2002). Tato. Yogyakarta: Institut Seni Yogyakarta.

Benny H. Hoed, 2011. Semiotik \& Dinamika Sosial Budaya, cetakan pertama, Beji Timur, Depok.

Kriyantono, Rachmad. (2008). Teknik Praktis Riset Komunikasi. Jakarta: Prenada Media Grup.

Kusbiantoro, Krismato. (2016). Modernisasi dan Komersialisasi Uma Masyarakat Mentawai Sebuah Deskripsi Fenomenologis. Jurnal Sosioteknologi, 15 (2), 187188. Mei $2019 . \quad$ Terarsip di: http://journals.itb.ac.id/index.php/sostek/article/view/2385/1529

Moleong, Lexy J. (2009). Metodologi Penelitian Kualitatif. Bandung: PT. Remaja Rosdakarya.

Moleong, Lexy J. (2010). Metodologi Penelitian Kualitatif. Bandung: PT. Remaja Rosdakarya.

Olong, Hatib Abdul Kadir. (2006). Tato. Yogyakatra: yayasan PT. LKis Pelangi Aksara.

Rosa, Ady . 1994. "Eksistensi Tato Sebagai Salah Satu Karya Seni Rupa Tradisional Masyarakat Mentawai" [tesis magister]. Bandung: ITB.

Ruambiati, Ambar Retno., \& Putra, Yanladila Yetlas. (2015). Konsep Diri Pada Masyarakat Mentawai yang Memakai Tato. Jurnal Psikologi, 2,114-125.

Sukmadinata, Nana Syaodih. (2009). Metode Penelitian Pendidikan. Bandung: Remaja Rosdakarya. 